\title{
Editorial
}

\section{Cómo comunicar malas noticias en la práctica médica}

\author{
How to Communicate Bad News in Medical Practice \\ Como comunicar más notícias na prática médica \\ Martha Tania Ramírez-Ibáñez* Omar Fernando Ramírez-de la Roche**
}

La mala noticia se define como aquella que altera o cambia la perspectiva del paciente y su familia de manera drástica y negativa; causa alteración emocional de forma adversa o grave, y afecta su visión futura. ${ }^{1} \mathrm{El}$ tema se ha investigado en todo el mundo, su interés aumentó en la década de 1980, debido a problemas como: la protección ante la respuesta agresiva del paciente en función de la seguridad física, reputación y aspectos legales contra el médico; y a causa de que el paciente exige mayor información sobre su enfermedad, debido al fácil acceso a los medios de comunicación. ${ }^{2}$ Esto ha generado la realización de manuales, protocolos y cursos; e incluso se han modificado leyes o reglas para dar las malas noticias.

Barley Buckman, en la Universidad de Toronto, desarrolló el protocolo más utilizado, denominado SPIKES:

1. Setting up: es preparar el entorno sin interrupciones, a fin de respetar la privacidad e intimidad del informado y la preparación profesional

2. Perception: es adecuar la información y explicar, con base en lo que sabe el paciente y lo que comprende; el manejo de la comunicación verbal y no verbal

3. Invitation: obtener la información y lo que desea saber el paciente
4. Knowledge: uso del vocabulario adecuado sin tecnicismos en la entrega de información

5. Emotions: mostrar empatía y emociones del médico al paciente y/o familia

6. Strategy and summary: se trata de disminuir la ansiedad, responder a las emociones y sentimientos del paciente y/o familia, además de tener un plan futuro

Otro protocolo es el ABCDE desarrollado por Rabow y Mcphee ${ }^{3}$ en la Universidad de San Francisco:

A. Preparación anticipada, sin interrupciones

B. Crear un entorno para una relación terapéutica

C. Comunicar bien, brindando contención y libertad de expresión al paciente

D. Tratar las reacciones con pacientes y familiares

E. Fomentar y validar las emociones

En Colombia, se ha estudiado el área de psicología del dolor y cuidados paliativos, la cual incluye no solo las noticias severas, sino las relacionadas con enfermedades crónicas, incapacidades o pérdidas funcionales; ya que tiene un componente objetivo: la severidad, y otro subjetivo, que es el propio paciente. ${ }^{4}$

En Venezuela, en 2009, se realizó un curso de comunicación de malas noticias con apoyo de la Organización Nacional de Trasplantes de Venezuela y de España para intervenir positivamente en el proceso de donación de órganos y tejidos. ${ }^{5}$

*Residente de la especialidad en Medicina Familiar. Subdivisión de Medicina Familiar, Centro de Salud "Dr. José Castro Villagrana", Secretaría de Salud Pública del Distrito Federal (SSPDF). Subdivisión de Medicina Familiar, División de Estudios de Posgrado, Facultad de Medicina, Este artículo debe citarse: Ramírez-Ibáñez MT, Ramírez-de la Roche OF. Cómo Universidad Nacional Autónoma comunicar malas noticias en la práctica médica. Aten Fam. 2015;22(4):95-96. de México (UNAM). 
En Brasil, se estudió la forma para comunicar las malas noticias en el área de Ginecología durante la atención prenatal, enfocándose en la experiencia de las pacientes; estas recomendaron decir la verdad en cada consulta a los familiares y/o acompañantes. ${ }^{6}$

En la Universidad de Chile, se desarrolló un taller para estudiantes de quinto y sexto año de la carrera de Medicina durante cinco años consecutivos (2006-2010) basado en tres ejes: el manejo de situaciones difíciles; la comunicación de las malas noticias a pacientes y familiares; y el autocuidado del profesional. $^{7}$

En Perú, se desarrolló un curso de comunicación en situaciones críticas sustentado en la triada: respeto, autenticidad y empatía, para comunicar malas noticias, el objetivo fue la ayuda emocional al receptor de la noticia, y al profesional para generar habilidades comunicativas. Se apoyaron en la proyección de películas dirigidas por Pedro Almodovar como: Flor de mi secreto y Todo sobre mi madre. ${ }^{8}$

En Argentina, se han realizado estudios en el área de Cardiología, se encontró que comunicar una mala noticia no es placentero y muchos médicos temen a la reacción del paciente o de la familia. Además analizaron los factores que afectan este entorno, como circunstancias sociales del paciente y del médico. ${ }^{9}$

En Europa también se ha estudiado la cuestión; en Portugal, en un estudio notaron que aunque el paciente se encuentre acompañado al recibir las noticias existen muchos problemas, sobre todo la diferencia entre la información que se les da y las necesidades de los pacientes; ${ }^{10}$ en la Universidad de Madrid, España, diseñaron un manual mediante el cual ofrecen las siguientes claves para mejorar la comunicación al dar noticias al paciente: perder el miedo a hablar desde una perspectiva emocional; dejar que el paciente lleve la iniciativa; respetar los derechos del paciente; transmitir esperanza sin engaños; no negar o desoír la expresión de emociones y su impacto; evitar frases que no consuelen; escucha activa; empatía; y ser creíble. ${ }^{11}$

En Francia, en una investigación se hallaron los factores de la baja comprensión en los familiares que recibieron malas noticias en una unidad de cuidados intensivos, lo que ha ayudado a los médicos franceses para mejorar la toma de decisiones e informar las malas noticias. ${ }^{12}$

En el Reino Unido, la British Medical Association (BMA) manifestó la importancia que tiene para un médico dar una mala noticia, ya que es una habilidad que se debe aprender, y recomendó el Manual de Medicina Clínica de Oxford que da consejos respecto a cómo comunicarlas. ${ }^{13}$

En Asia también se estudia el fenómeno, por ejemplo, en Irán se exploraron las experiencias de un grupo de madres al recibir el diagnóstico de cáncer en sus hijos, debido a que la comunicación de las malas noticias afectan al individuo por la forma en que se reciben, interpretan y entienden. ${ }^{14}$

Como se puede observar, la entrega de malas noticias ha sido exhaustivamente indagada en el segundo y el tercer nivel de atención, en la comunicación de diagnósticos graves o incapacitantes; es imperioso realizar estrategias educativas enfocadas al personal médico en formación para el primer nivel de atención, en el cual los pacientes, familiares o acompañantes recibirán los resultados una gran gama de padecimientos crónicodegenerativos que afectarán en mayor o menor medida a la integridad del individuo y la familiar.

\section{Referencias}

1. Adebayo PB, Abayomi O, Johnson PO, Oloyede T, Oyelekan AA. Breaking bad news in clinical setting - health professionals' experience and perceived competence in southwestern Nigeria: A cross sectional study. Ann Afr Med. 2013;12:205-11.

2. Ártus A, Beux V, Pérez S. Comunicación de malas noticias. Revista Biomedicina: Medicina Familiar y Comunitaria. 2012;7(1):28-33.

3. Rabow MW, Mc Phee SJ. Beyond breaking bad news: how to help patients who suffer. West J Med. 1999;171:260-3.

4. Payán GC. Comunicar malas noticias: una tarea difícil pero necesaria. CIRUPED. 2012;2(1):35-9.

5. Programa Integral Europeo para la Donación de Órganos (EDHEP), Organización Nacional de Trasplantes (ONTV) y Ministerio de Sanidad y Consumo de España. Curso: Comunicación de malas noticias. 2009; Caracas, Venezuela.

6. Ramos GF, Mirlesse V, Rodriguez BA. Breaking bad news during prenatal care: a challenge to be tackled. Ciência \& Saúde Colectiva. 2011;16(5):2361-7.

7. Bascuñan RM. Taller de manejo de situaciones difíciles, comunicación de malas noticias y autocuidado del profesional. Evaluación según la percepción de los participantes. Rev Educ Cienc Salud. 2011;8(1):31-7.

8. Zapata L. Transmitir malas noticias, la efectiva comunicación en el sector salud. La revista Oficial del DirCom, imagen y comunicación. 2013;41:11-5.

9. Alves DL. Cómo comunicar malas noticias a nuestros pacientes y no morir en el intento. Revista Argentina de Cardiología. 2003;71(3):217-20.

10. Ferraz GA, Marques A, Rocha S, Letião P, Mesquiña T, Moutinho S. Malas noticias. Unidad de cuidados paliativos. Instituto Portugues Oncologóia Oporto. 2005;19(7)526-31.

11. De los Reyes López M. La comunicación con el enfermo. Consideraciones en la UCIC. En Feito Grande L, editor. Estudios de bioética. Madrid, España: Universidad Carlos III de Madrid. Instituto de Derechos Humanos "Bartolomé de las Casas"; 1997. 162.

12. Ricart A. La comunicación en Medicina Intensiva. REMI: Libro electrónico de Medicina Intensiva. 2008;3(6)sección de ética.9:264-8.

13. Breaking bad news: specialty register in general surgery. National Council for Hospice and Specialist Palliative Care Services. British medical association [Internet]; 2003. Disponible en: www.bma.org.uk/ developing-your-career/foundation-training/reallife-advice/breaking-bad-news

14. Fereshteh AE, Delaram M. Giving bad news: a qualitative research exploration. Iran Red Crescent Med J. 2014;16(6):e81971. 